\title{
18 Everyday reality at nursing home care facilities experienced during the COVID-19 pandemic
}

\author{
Małgorzata Halicka, Jerzy Halicki \\ and Krzysztof Czykier
}

Most studies on COVID-19 and ageing are primarily concerned with analysing the issue from a medical science perspective, as ageing itself is an important risk factor for severe illness and death due to COVID-19. However, it must be remembered that the SARS-CoV-2 pandemic, in addition to its profound and still unfolding health effects, also leaves its mark on the daily functioning of older people, both socially and emotionally. In a situation of compulsory isolation, a group particularly vulnerable to loss of meaning and existential comfort are older adults living in social care facilities. In this chapter we would like to share with our readers the opinions of the residents of such facilities regarding their personal experiences of living everyday life in the reality of the coronavirus pandemic.

\section{Introduction}

Humanity lives in an environment dominated by micro-organisms, which constitute $99.99 \%$ of all living creatures that inhabit the Earth. Each of us carries billions of such creatures without realizing that they are our best friends and most dangerous enemies. Some help us digest our food, others cause disease and epidemics (Harari 2014). Most of the infectious diseases that have plagued agricultural and industrial societies originated in domesticated animals and passed on to humans after the agrarian revolution. People living in hunter-gatherer cultures, who had only domesticated the dog, did not experience these misfortunes. Moreover, in agricultural and industrial societies, most people lived in cramped, unhygienic conditions that were a hotbed for diseases (Harari 2014).

Epidemics can change history. The best example of this is the Plague that has re-appeared several times over the centuries. It decimated the population for the first time in the 6th century. With Constantinople at its centre, it lasted only one year and claimed 25 million lives. In the centuries that followed, the Plague killed twice as many people and, according to historians, was 
instrumental in ending Rome's rule. The bacteria causing the Plague came from the East, most likely from China along the Silk Road (Rutherford 2016).

Another Plague epidemic, known as the "Black Death," broke out in China or Central Asia, reached Crimea in 1346, and spread from there to the Mediterranean and to Europe. The disease killed around 200 million people. Plague outbreaks appeared quite regularly until the 18th century (Harari 2014).

In the 16th century, a smallpox epidemic broke out in South and North America, decimating the indigenous peoples of these continents (the Incas and the Aztecs). Plague epidemics broke out in America many times in the second half of the 17th century. The 18th century European Plague epidemic took the lives of some 60 million people. In the 19th century, Plague and cholera pandemics swept the world, claiming over 50 million lives. The 20th century was also not free of epidemics. The biggest of these was the Spanish flu epidemic that broke out in 1918-1919, hit almost all continents, and caused the death of millions (according to various estimates, between 20 and 100 million people). Humanity in the 21 st century is experiencing yet another plague - the COVID-19 pandemic, which has affected people all over the world.

Many questions can be asked about human helplessness in the context of a deadly universal disease. In this situation, it is difficult to argue with the restrictions introduced not only in social welfare institutions, but in all spheres of social life, in order to counteract the spread of the Sars-Cov-2 virus, commonly known as the coronavirus. These actions affected various areas of human life, such as the economy, interpersonal relations, and health. These new regulations have also had an impact on how social care homes work with their residents. The new legal regulations aimed at limiting the spread of the coronavirus caused the institutions to close off from the outside world: family visits and visits to specialists were suspended. The sudden change in the way care facilities operate in Poland and the new regulations made the institutionalization of residents more intense.

In this chapter we want to share with the readers the opinions of the residents of a nursing home regarding their personal experiences related to their daily life during the coronavirus pandemic. We want to show how they dealt with everyday life in this unusual situation. What were the emotions they felt? How did staff carry out their tasks in such an incredibly difficult situation of complete isolation? Could the residents of the facility count on the support of the staff and could the employees of the facility count on the support of the city or regional authorities? We also wanted to learn from the respondents how helpful the clergy were in this situation.

\section{Characteristics of the respondents ${ }^{1}$}

As much as 181 residents live at the Nursing Home in Białystok (Podlasie), but not all of them agreed to participate in the study. Their reasons varied, but most often it was bad health. In a few cases, the residents of the facility were 
reluctant to talk about the coronavirus. Under these extremely difficult conditions, we were able to recruit 35 people to interview. This group included 12 women ( 4 women under 70 and 8 women aged 70 or more) and 23 men (13 of them were not older than 70 and 10 have reached 70 or more years of age). In terms of education, the majority had secondary education (16 people, including eight women and eight men), 13 people (nine men and four women) received vocational education, while six men had primary or incomplete primary education. As far as marital status is concerned, they were mainly unmarried (31 people), including 13 divorced (mainly men -10 people), 10 widowed (six women and four men), while those who had never married were mainly men (7 of them) and only one woman. The largest group of respondents consisted of the deeply and actively religious. Among 16 such people, there were nine men and seven women. There were 13 non-participating believers (nine men and four women), five religiously indifferent respondents (four men and one woman), and only one man who declared himself to be a non-believer. Most of the respondents (14 men and nine women) had children. It is, however, noteworthy that nine men had no children, while only three women were childless. Analysis of the socio-demographic characteristics of the sample explains, in a way, why they ended up living in a care facility.

The results of our research carried out in the group of people described above will be presented below, in relation to three problem areas: the knowledge of the residents of the facility about the coronavirus, the feelings of the residents related to the coronavirus situation, and interpersonal relations during the pandemic. These analyses will be complemented by reports of two professionals employed in two institutions: the nursing home in Białystok, where there was no confirmed outbreak of the coronavirus but full isolation of the residents was nevertheless introduced, and in the nursing home in Choroszcz, where there was a COVID-19 outbreak, as reported by one of the social workers who took care of residents at a COVID sub-unit. ${ }^{2}$

\section{The residents' knowledge about the coronavirus}

All the residents of the nursing home in Białystok had some knowledge about COVID-19. The respondents' statements indicate that they were aware of the vectors and symptoms of infection, the course of the disease, groups of people particularly susceptible to infection, and the possible consequences of infection, including death. Examples: "The virus originating in China from a bat" (W, 72 years old), "It is an infectious disease transmitted by airborne droplets" (M, 71 years old), "Dangerous virus, comparable to biological weapons" (M, 70 years old), "A virus causing respiratory diseases in people over 65 " (M, 64 years old). It is worth adding that a few respondents (four men and two women) have been tested for the coronavirus.

Despite the fact that there were no people infected with the coronavirus among the respondents, they were able to indicate typical somatic symptoms accompanying the disease caused by the coronavirus, i.e., increased 


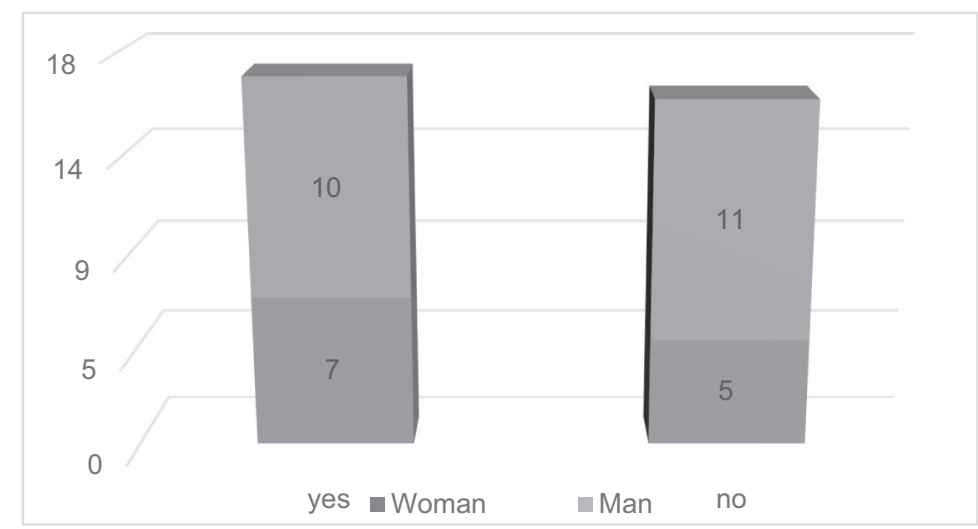

Figure 18.1 Coronavirus training conducted by care home staff

body temperature, cough, shortness of breath, general weakness, lack of a sense of taste and smell. Only one person (male) had known or heard of an acquaintance infected with the coronavirus. However, it should be mentioned that the research was carried out in June 2020 (three months from the introduction of the first restrictions and isolation) before the escalation of infections among older people, including care home residents.

The respondents were not able to clearly determine whether the facility staff instructed them about the coronavirus. Perhaps this was due to the fact that most often the activities meant to improve the residents' awareness of COVID-19 took the form of talks or individual conversations (Figure 18.1). The interview with a director of the facility indicates that many conversations regarding the coronavirus were conducted with the residents.

Thanks to the information about the coronavirus provided by the institution's staff, the residents displayed knowledge of the principles of the facility's functioning in the time of a pandemic and knowledge of the applicable procedures. Each of the respondents pointed out without hesitation the need to inform the caregivers or the facility staff, should suspicious symptoms be noticed in a fellow resident, which could indicate a coronavirus infection. An example of one transparent statement: "Inotify my superiors and caregivers immediately" (M, 60 years old).

The respondents also correctly listed activities related to the prevention of infection. According to experts, today, in the face of the second wave of infections, these activities are the basic and most effective forms of preventing the spread of the virus.

In the opinion of the respondents (both men and women), the most important thing in preventing coronavirus infection is frequently washing or disinfecting hands (Figure 18.2).

It is also important to use protective masks (of the right type, in the right way, and in certain situations) and to keep a distance in relations with other 
40

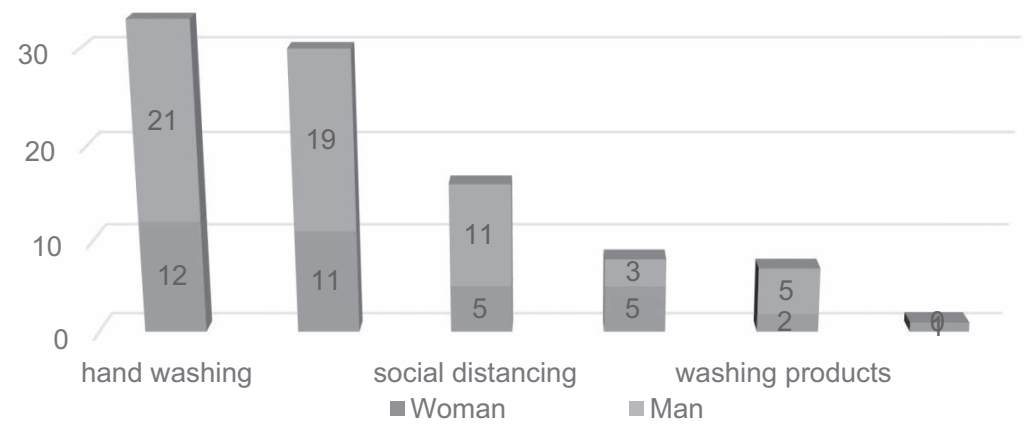

Figure 18.2 Prevention of SARS-CoV-2 coronavirus infection

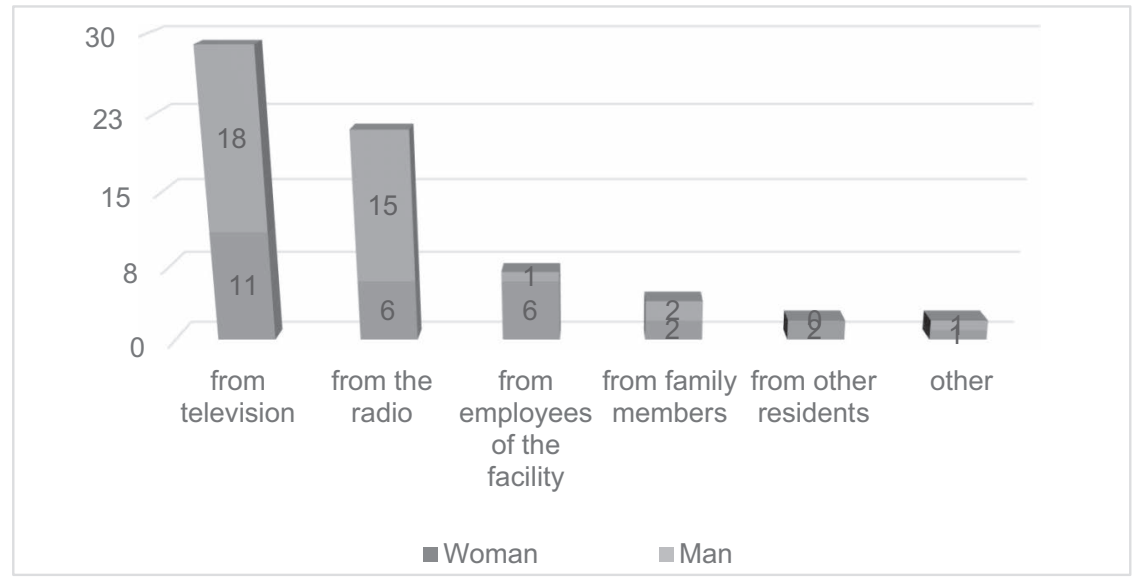

* respondents could choose multiple answers

Figure 18.3 Sources of knowledge about the coronavirus

people. It is also important to disinfect surfaces and objects of everyday use and to maintain hygiene when preparing meals.

As mentioned earlier, the employees of the facility are an important source of knowledge about the coronavirus for the residents.

Most frequently, however, the respondents obtained daily updates on the pandemic from the media - television and radio (Figure 18.3). Family members (mainly through indirect contact) and other residents are also an important source of knowledge. 
In the nursing home where the research was carried out, as in every institution in the field of social welfare and health care, strict security measures were introduced to ensure the protection of residents against coronavirus infection. In the opinion of the respondents, first of all, an absolute ban on visits was introduced in their institution (Chart 4). Every participant knew it and pointed it out (Figure 18.4).

Residents are also forbidden to go outside the facility and to hold and participate in religious services (this was more often indicated by men). Statistical analysis shows a weak relationship between the variables $\left(C_{\text {kor }}=0.25\right)$, however the differences are not statistically significant $(\mathrm{df}=2 ; \mathrm{p}=0.5276)$.

Most of the respondents (17 men and 12 women), despite having lived for many years, claim to never have met a person who had suffered from any infectious disease. Although statistical analysis shows a weak relationship between the variables $\left(\mathrm{C}_{\mathrm{kor}}=0.35\right)$, the differences are not statistically significant ( $\mathrm{df}=2 ; \mathrm{p}=0.2724)$. Most of the respondents (19 men and 10 women) had not experienced any infectious diseases personally.

\section{Emotional responses to the coronavirus}

The relative health of the respondents, at least in the context of infectious diseases (as described above), caused something of a shock in the face of the COVID-19 pandemic, triggering deep feelings of fear, anxiety, and uncertainty about life. Among the feelings accompanying them at the beginning of the pandemic, the respondents most often indicated anxiety, fear, and stress (Figure 18.5). The new, unexpected situation caused a deep concern for their health and life, as well as that of their friends and loved ones.

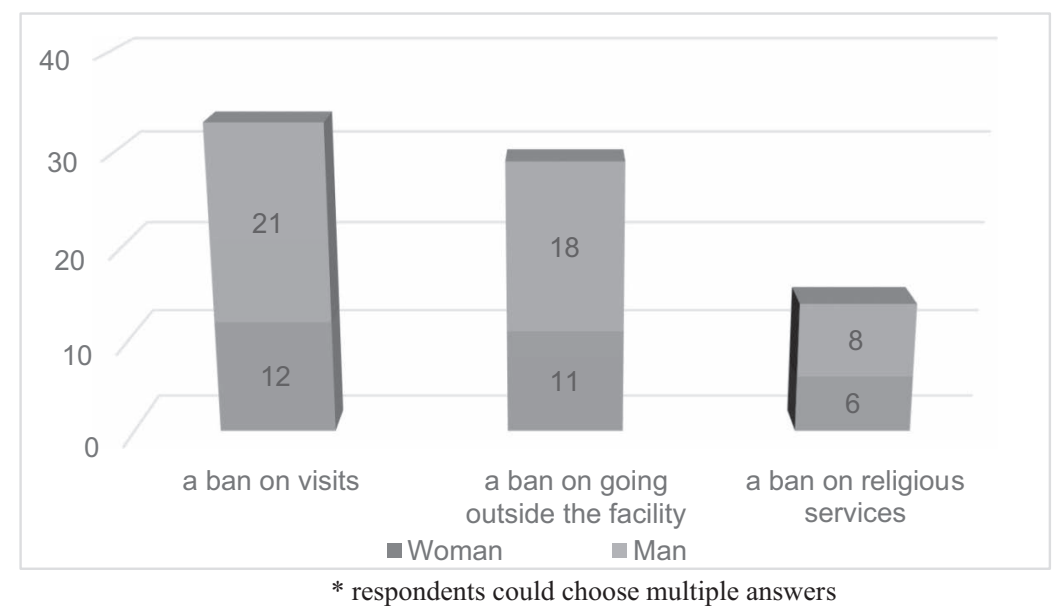

Figure 18.4 Security measures introduced in the care home for the prevention of coronavirus infection 


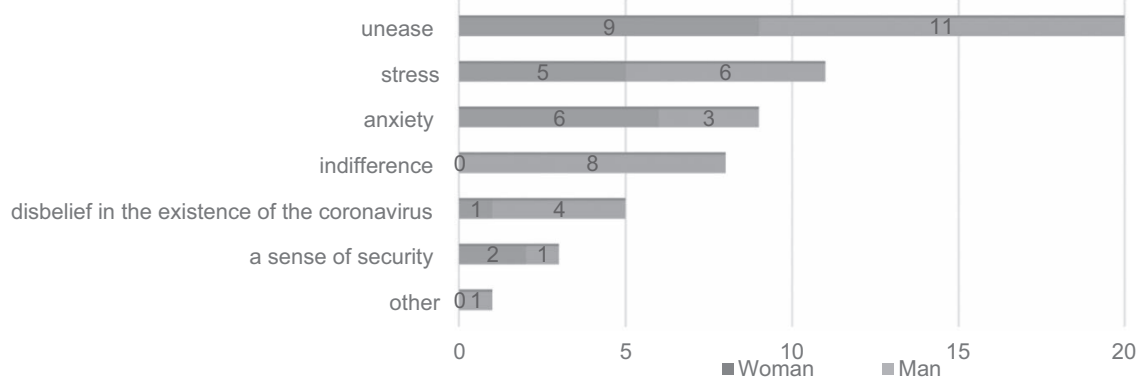

Figure 18.5 Emotions felt by the respondents at the beginning of the pandemic

It is interesting that men, more often than women, were indifferent to the situation, a feeling supported by their disbelief in the existence of the coronavirus. Perhaps it was a consequence of the experience of sudden change that no one was prepared for, a peculiar mechanism of optimistic rationalization, or of repression and denial of the improbable. It is important that some (albeit only a few) of the residents expressed a sense of security, which should be treated as a sign of trust towards the staff.

Interestingly, at this time, after several months of living with the coronavirus pandemic, the respondents experience similar feelings as at its beginning: "Anxiety, fear of infection" (W, 67 years old), "High stress and terror" (W, 66 years old), "Indifference" (M, 69 years old), "The same" (M, 72 years old), "A sense of security" (W, 87 years old). There was also a sense of fatigue, helplessness, and habituation.

These opinions are expressed in the respondents' declarations about what has changed in their perception of the pandemic situation (Figure 18.6). Among these opinions, the feeling of getting used to the situation caused by the pandemic prevails, more so for men than for women.

The isolation of the residents is born of necessity and subject to formal regulations. It is also reflected in the fatigue they feel, mainly caused by the prohibition on direct contact with family and on leaving the facility. An interview with a social worker from the COVID-19 sub-division shows even more of the complexity of the situation and the emotions felt by employees as well in this life-threatening situation. Here is the account of the social worker:

Each subsequent piece of information regarding the positive results of a staff member or resident increased the feeling of exhaustion, tension, fear, uncertainty, hopelessness, and sadness. The first thing I experienced when entering the COVID ward was silence, peace, and a sense of horror, resulting from how I imagined working in such conditions, while I was presented with information on the general rules of conduct. At the beginning it was 


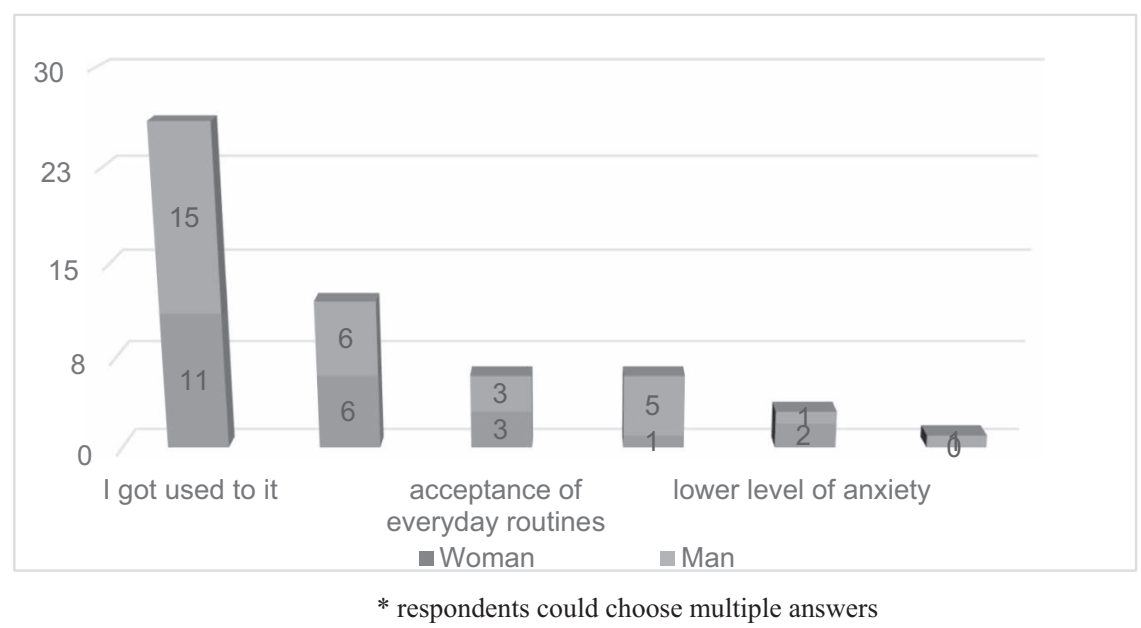

Figure 18.6 Perceptions of the pandemic at the time of the research

exhausting to have to stay focused while putting on all the layers of suits, being careful not to touch the eyes and mouth and during the disinfection process after leaving the COVID ward.

The surveyed residents also expressed acceptance for everyday life as it is. Some respondents claimed that nothing had changed over the three months. The lowest level of anxiety, which was indicated by only a few respondents, may be a consequence of "taming the coronavirus," i.e., learning about the mechanisms of the pandemic, gaining knowledge about protection options and prevention, and learning to live anew in a situation of COVID-19 isolation.

More than half of the respondents try to conduct their everyday life with a sense of security (Figure 18.7). Every third respondent is unable to clearly define their sense of their own security - sometimes they feel safe, other times they do not.

The residents who participated in the research also experienced a feeling of loneliness. During the pandemic, it is a part of the experience of many older people, including the residents of care homes. The situation of total social isolation of the respondents, expressed mainly in the lack of direct contact with the family, significantly deepens the feeling of loneliness. Experiencing a sense of loneliness is common to almost all the respondents. It was confirmed by more than half of men and almost all women (Figure 18.8).

Men said that they often felt lonely more frequently than women. Most women, on the other hand, feel lonely at times. Statistical analysis shows a strong relationship between these variables $\left(\mathrm{C}_{\mathrm{kor}}=0.64\right)$ and the differences are statistically significant $(\mathrm{df}=3 ; \mathrm{p}=0.0112)$. Several of the surveyed men stated that they did not experience a sense of loneliness. There were also 


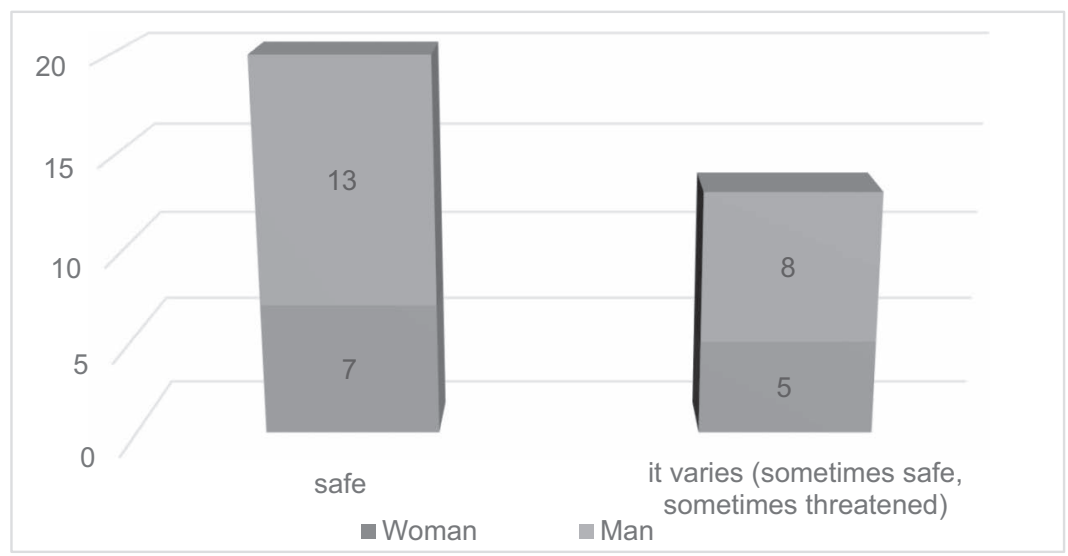

Figure 18.7 Sense of security among the surveyed residents

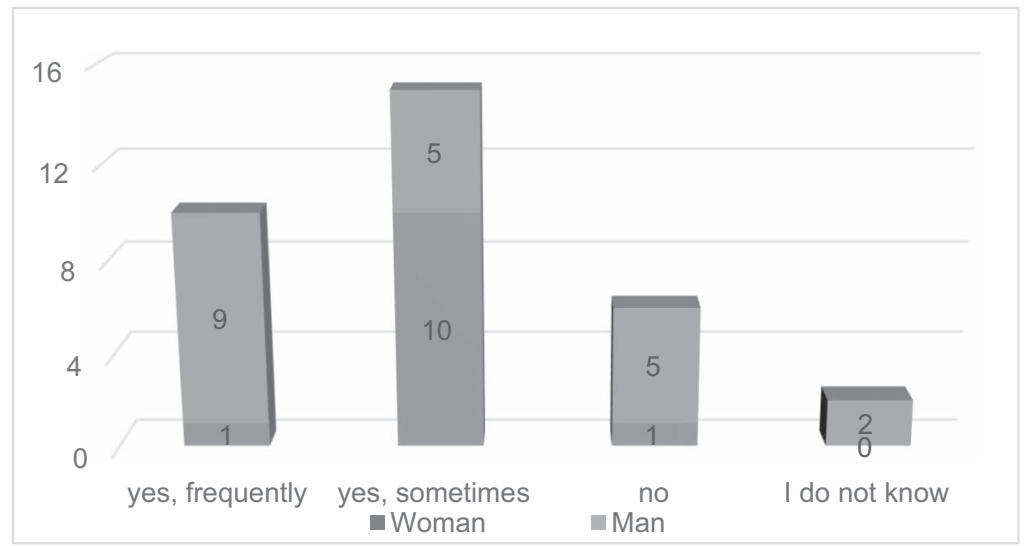

Figure 18.8 The feeling of loneliness among the respondents

those who were unable to take an unequivocal position on this issue. The account of a social worker explains this situation in a way. In his opinion,

At the stage of introducing further restrictions in the facility, resulting from the general epidemiological situation in the country, a coronavirus outbreak in the facility and staff shortages, the feeling of institutionalization and isolation of the residents was growing. For safety reasons, the activities of therapeutic and physiotherapy laboratories and the gym were suspended. The residents were not able to go out into the fresh air. Thus, social rehabilitation, that is, the organized interdisciplinary work of 
empowering residents, treating the participant in a holistic manner, was not possible to a wider extent. This resulted in loneliness, decreased activity, frequent mood swings, depression, as well as excessive agitation, and in extreme cases even acts of aggression.

In their statements, residents pointed out situations that could contribute to the improvement of their well-being. Among the most frequently repeated expectations was a longing for contact with the family and going outside the facility. Residents also pointed towards a more rigorous adherence to the established rules of SARS-CoV-2 prevention. There were also statements expressing a desire to return to what life was like before the outbreak of the COVID-19 pandemic. Examples of statements: "Allow for meetings with family" (W, 78), "Let us out, let our families in" (M, 57), "Obey the prescribed rules" (M, 70), "The facility should be as it used to be" (M, 70). According to the director of the facility,

the lack of broader relations, including with the external social environment, the uncertainty of tomorrow, the lack of prospects, the inability to participate actively in Holy Mass celebrated every Sunday in the facility filled the residents with doubt, pessimism, and disbelief in quick change.

\section{Interpersonal relations in the facility during the pandemic}

We understood interpersonal relations in a care institution in a pandemic situation in two dimensions: as the relationships between residents and staff and as relationships between residents. Concerns about coronavirus infection in their contacts with staff during the pandemic were experienced by 13 respondents, which means that people who did not have such fears constituted the majority.

An even greater number of respondents did not feel any concern about contracting the coronavirus through their contacts with the residents of the facility (22 people). It is noteworthy that men experienced a lack of such concerns twice more frequently than women (15 and seven respondents respectively). Only some people occasionally have such concerns. It is probably related to the knowledge and belief of the residents that no coronavirus outbreak was found in the facility, hence the positive attitude and greater sense of security.

Positive assessment of the relationships between fellow residents is a cause for optimism. This is evidenced by the data presented in Figure 18.9, which shows that 19 people assessed their relations with other residents as good, while 4 men assessed them as very good.

Eight men and four women have an ambivalent attitude towards their relations with other residents. These people evaluate the relationships as neither good or bad, so they could be considered unsatisfactory. Two of the respondents (one woman and one man) do not maintain any relations 


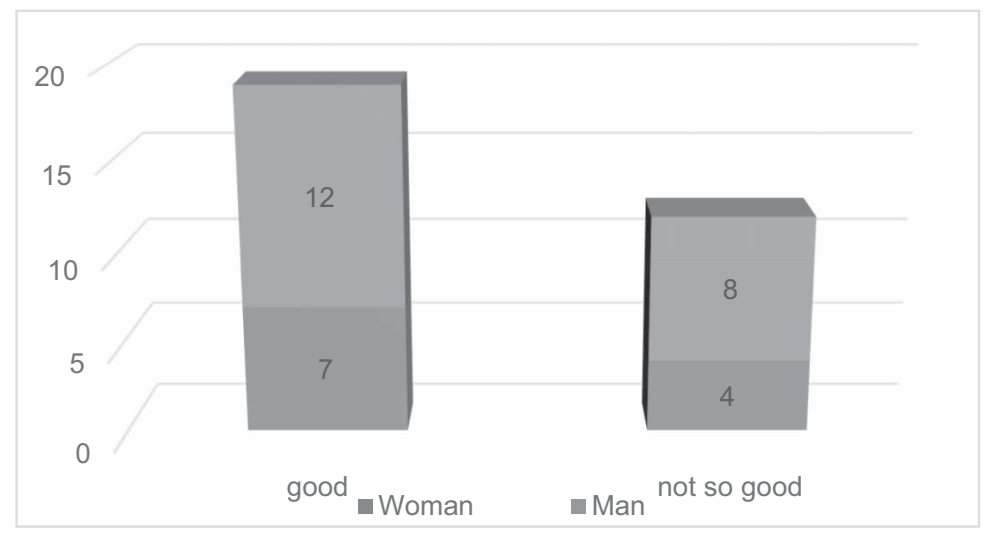

Figure 18.9 Assessment of relations with other residents

with anyone. Perhaps it is related to the individual personality traits of the respondents.

About two-thirds of the respondents answered "yes" to the question "Is the ban on visiting the facility justified?" However, it is noteworthy that 15 of them expressed the opinion that the ban is only partly correct.

The respondents generally negatively assessed everyday life and changes in the facility brought on by the coronavirus. In their opinion, the unfavourable changes relate primarily to the ban on leaving the facility, the ban on visits that they miss and wait for, pointlessly sitting in one place, a feeling of emptiness, monotony, lack of perspectives. This assessment was complemented by the possibility for the respondents to point out three of the most important deficiencies in their experience of daily life in institutional conditions during the pandemic. It showed that the residents suffer the most from a lack of a sense of freedom expressed in freedom of movement outside the facility. This was the opinion of 25 people, only five of whom were women (Figure 18.10). It may be presumed that for some men the lack of freedom to move outside the facility is related to the inability to purchase alcohol. It is no secret that many of them are addicted to it. In the respondents' opinions, the inability to have direct contact with the family is equally important. Nineteen respondents pointed out the inability to meet this need.

A few people indicated that the thing they miss the most is the ability to participate in religious services, which are not held in care homes due to pandemic restrictions. It should be noted that the residents of the facility did not express any other expectations of the staff of the facility, apart from the wish, expressed by four people, that medical visits to the residents would be more frequent. It was the wish of the respondents in the care of the facility that all the residents would be tested and that the pandemic would end. 


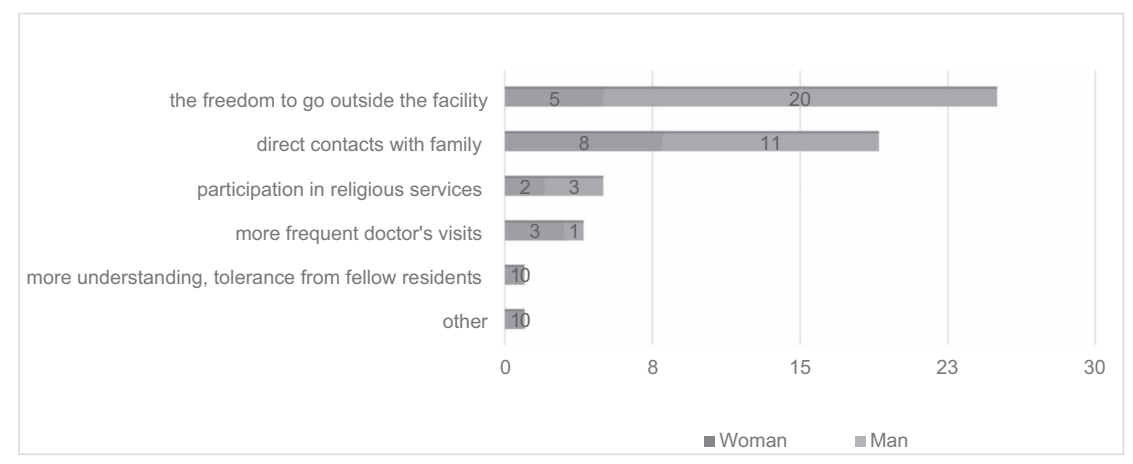

Figure 18.10 The needs of institutional residents during the pandemic

The residents were grateful for the care provided by the employees of the facility and expressed their thanks to the director.

The opinion of a social worker sheds light on the good practices that allow the residents' needs to be met. In his opinion,

efforts are necessary to prevent the residents - as far as possible - from experiencing the negative effects of increased isolation. Modern technologies have been used to diversify social rehabilitation. In order to build a friendly atmosphere in the COVID sub-unit, enabling the creation of a sense of security and peace, we engaged residents in joint, small scale work in the ward, depending on their health, often with music played from a large [...] loudspeaker.

Residents reacted positively to activities that brought variety to everyday life. According to the social worker, private equipment belonging to one of the members of the three-person team was used, specifically a projector and a large screen to display media selected by the residents, i.e., a movie of their choice in the evening, playing relaxing music during the day, or playing computer games together (on a laptop). In the opinion of the social worker,

the implementation of social rehabilitation in this way was meant to provide a substitute for "normality". To meet the needs of the residents, we also managed to organize a birthday party for one of them, attended by all the residents of the COVID sub-unit. While working in the covid sub-unit, we would every day notice new problems of the residents, which made it impossible for them to meet their life needs; one of them was the inability to contact the residents staying in the "healthy" sub-units. We met this challenge using the projector, the Internet, and the Messenger app to communicate; using the web and a webcam we called a carer working in 
the "healthy" sub-unit with a request to share the screen with us and allow friends to see each other and talk remotely. Going further to meet the residents' needs, we began to contact other sub-units in the same way, so that the residents could talk to other people together

The interview with the social worker made us aware of another problem, namely the threat of professional burnout in extreme situations, such as the coronavirus pandemic.

A situation of increased isolation, implementation of new obligations regarding systematic disinfection of the premises, the need to pay special attention to everyday work, increase the probability of the onset or deterioration of burnout symptoms. The tense atmosphere led to many verbal conflicts between the staff, which did not facilitate overall communication and cooperation in combating the coronavirus outbreak at the facility. Chronic stress, tension, a sense of hopelessness resulting from prolonged work hours, incoming information about new coronavirus infections and deaths, meant that even an inconspicuous problem or noticing some irregularity could cause an inadequate reaction to the situation. For this reason, the employees received additional psychological support.

Everyday life experienced by the residents and staff in a care institution during the coronavirus pandemic is a very complex problem and difficult to deal with without the involvement and support of authorities. Official sources tell us that during the coronavirus pandemic the facility where the research was carried out could count on cooperation and support from local authorities, while it was much more difficult to find understanding and support from regional authorities. And yet the needs of the residents of aid institutions should be equally important to those in power both in the city and in the region.

\section{For further discussion...}

The social situation related to the emergence of the coronavirus has changed a lot in the life of every person, but the everyday life experienced in the reality of the coronavirus pandemic by the residents of care facilities and the staff employed there has - as we tried to show above - a specific character. Regardless of whether coronavirus outbreaks occurred in the facility or not, it was necessary to implement new procedures to counteract the spread of the virus. However, these steps strengthened the institutionalization of the inhabitants and their feelings of isolation. A lack of direct relations with the family and a lack of relations with the outside world negatively affected the general well-being of the residents, as well as the staff.

In these difficult, rapidly changing conditions for the functioning of a nursing home, both residents and employees had to go on with their daily 
lives. In a situation of total isolation resulting from the public health restrictions they were in a way forced together and the hitherto routine daily activities turned out to be a challenge.

The statements of the surveyed residents and employees point towards a dynamic in the emotions they experienced and the nature of interpersonal relations in the facility - from initial fear, panic, through indifference, coming to terms with the situation, to relative peace and mutual trust and cooperation. There is no doubt that the isolation experienced by the care home residents and staff members can be seen as a situation of crisis.

When looking for the bright sides of the situation (which is very difficult due to the global and lethal scope of the pandemic), one should remember that every crisis creates the potential to get out of it stronger. Disturbed by the pandemic, long-lasting relationships within the care home, reformulation of the employee ethos, and limited support for the functioning of the institution from external entities, constitute new areas requiring the development of new standards in the post-COVID reality.

\section{Notes}

1 The chapter is based on empirical research conducted among the residents of a Nursing Home in Białystok in 2020 after the outbreak of the pandemic. The research tool was a questionnaire. A diagnostic survey was used as the research method. Due to the complete isolation of the residents, the research was carried out by two employees of the facility using a research tool prepared by the authors. In some cases, the respondents did not answer all the questions. Two telephone interviews with the employees of the facility were also conducted. The research results are presented as absolute numbers.

2 At this point, we would like to thank the Directors of the nursing homes in Białystok and Choroszcz and their employees for enabling us to conduct the research and for the interviews. We also want to express our gratitude to the patients for agreeing to participate in the research. Carrying out scientific research in the difficult conditions of a pandemic was not an easy task. All the greater is the satisfaction of achieving what we thought was impossible.

\section{References}

Harari Y.N. (2014), Sapiens. A Brief History of Humankind. London: Harvill Secker.

Rutherford A. (2016), A Brief History of Everyone Who Ever Lived. London: Weidenfeld and Nicolson. 